\title{
Knowledge Engineering Research Topic Mining Based on Co-word Analysis
}

\author{
Xiumin Liu \\ National Science Library \\ Chinese Academy of Sciences \\ Beijing, China \\ liuxiumin@mail.las.ac.cn
}

\author{
Zheng Liu \\ National Science Library \\ Chinese Academy of Sciences \\ Beijing, China \\ liuz@mail.las.ac.cn
}

\begin{abstract}
This paper collects research papers on knowledge engineering 2009-2018 from the internationally-authoritative citation database Web of Science and uses the co-word analysis method to analyze these contents of literature. By statistical analysis of keyword frequency, the paper compiles the co-word table of the high-frequency words, uses statistical analysis software to make hierarchical clustering, and summarizes hot research topics in the knowledge engineering area.
\end{abstract}

Keywords-knowledge engineering; co-word analysis; topic research; data process

\section{INTRODUCTION}

In 1977, Professor B.A. Feigenbaum, a computer scientist at Stanford University in the United States, presented a new concept of knowledge engineering at the 5th International Conference on Artificial Intelligence. He believes that "knowledge engineering is the principle and method of artificial intelligence, providing a means to solve problems that require expert knowledge to solve. The proper use of the knowledge acquisition, expression and reasoning process composition and interpretation is based on knowledge. An important technical issue of the system." This type of knowledge-based system is an expert system built through intelligent software.

The method of co-word analysis was first described in detail in the mid to late 1970s by French biometrician. Coword analysis is a content analysis technique that uses patterns of co-occurrent of pair of items (i.e., words or noun phrases) in a corpus of texts to identify the relationships between ideas within the subject areas presented in these texts [1].

Based on the co-occurrence frequency of pairs of words or phrases, co-word analysis has proved to be a powerful tool for knowledge discovery in databases. Word clustering has also been profitably used in the automatic classification of documents, see [2]. The underlying assumption is that words that typically appear together should be associated with similar concepts.

10.18293/SEKE2019-047

\section{DATA SOURCE}

This paper uses the international authoritative citation database Web of Science published by the American Institute of Scientific Information (ISI) as the source of literature information. The paper intends to analysis the knowledge engineering research topics, so that the search criteria are "topic or search keyword is knowledge engineering", the search scope is 2009-2018, and the search time was February 122019 in the web of science database. The database has the added categories for each topic for more e. In the "knowledge engineering" subject, the "computer science interdisciplinary applications" or "computer science artificial intelligence" categories have been chosen for the limitation of the papers' content. A total of 1550 related articles were retrieved. Each article record contains multiple fields, such as title, author keywords, citations, publication date, etc.

\section{RESEARCH METHOD}

This paper uses the methods of bibliometrics and content analysis to quantitatively and qualitatively analyze the data. The Bibliometric Method is a quantitative analysis method that uses mathematical statistics to study the external features of the literature. Content Analysis Method is an in-depth analysis of the content of the research object [3].

There are two types of keywords in the research papers. One is author keyword (DE field), the other is a supplementary keyword (ID field) ISI keyword which is extracted by ISI according to the title of the paper. In order to fully reflect the topic of research in the field of knowledge engineering in the past ten years, using the author keywords.

After the DE field is split with punctuation ";", the list of keywords is formed. In the former similar papers directly used the form co-occurrence to establish a co-word matrix, this article will further summarize the word forms differently. Lemmatization rules apply to the keywords list. Lemmatization is a process of assigning a to each word form in a corpus using an automatic tool called a lemmatizer [4]. Lemmatization reduces inflected forms of a word to their lexical root. With lemmatization turned on, a keyword is reduced to its "lemma". As a result, lemmatization can reduce or eliminate the variant spellings of a word express the same 
concept. For example: citing 、 cites 、 cited and citation are the inflected forms of the cite. Lemmatization makes the mapping between cite and its each inflected form. In this paper, stemming rules also apply to the keywords processing. With stemming, words are reduced to their word stems. A word stem need not be the same root as a dictionary-based morphological root, it just is an equal to or smaller form of the word [5]. Stemming removes suffixes such as -ing and -es from keyword in order to cluster relevant keywords. For example, with stemming rules the keywords "vinyl recording" will be same as vinyl record. Stemming and lemmatization are closely related. The difference is that stemming merely drops suffixes such as -ing and -es, while lemmatization makes use of dictionaries that define pairs and clusters (e.g., defense, defenses) of words with the same meaning or with a shared morphological structure. Both lemmatization and stemming apply only to English language search terms. After the prototyping process, calculate the keyword frequency. Get the lemma keywords list with frequency.

From the literature of 1550 articles, the author keywords were merged through prototyping and stemming, and more than 4,000 concepts were obtained. On the basis of highfrequency word statistics, a co-occurrence matrix as TABLE I is established according to the frequency selection highfrequency keywords which frequency is greater than or equal to 10 .

In the construction of the author's key common word matrix, this paper uses the Python program to prototype and stem the author keywords to establish a $203 * 203$ matrix. The matrix is a symmetric matrix in which the data on the main diagonal is defined as the conceptual frequency, and the data on the non-main diagonal represents the number of times the two concepts appear together in the same paper. The concept here can be composed of multiple forms.

\section{BIBLIOMETRIC ANALYSIS}

\section{A. Published Time Distribution}

The change in the number of academic papers is an important indicator for measuring the development trend of a field for a period of time. It is of great significance for evaluating the stage of the field and the development trend and forecasting future trends. The author makes diachronic systematic statistics on the distribution of 1550 documents, and makes a distribution curve scatter plot, as shown in Fig. 1.

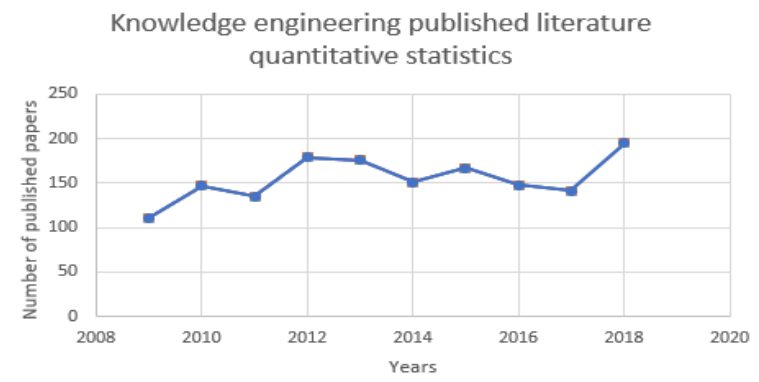

Figure 1. knowledge engineering published literature quantitative

It can be seen from the figure that the number of publications in knowledge engineering research has been growing steadily in the past decade, especially in 2012 and 2018, respectively, with two small peaks, 179 and 195. It shows that the industry has always attached great importance to the research of knowledge engineering, and knowledge engineering is still the current research hotspot.

\section{B. Publications}

Through statistical analysis, it is concluded that the top 24 journals published the most published papers accounted for $50 \%$ of the total papers in the entire knowledge engineering field. The journals of papers amount distribution as Fig.2. Providing high-quality academic papers for researchers in the

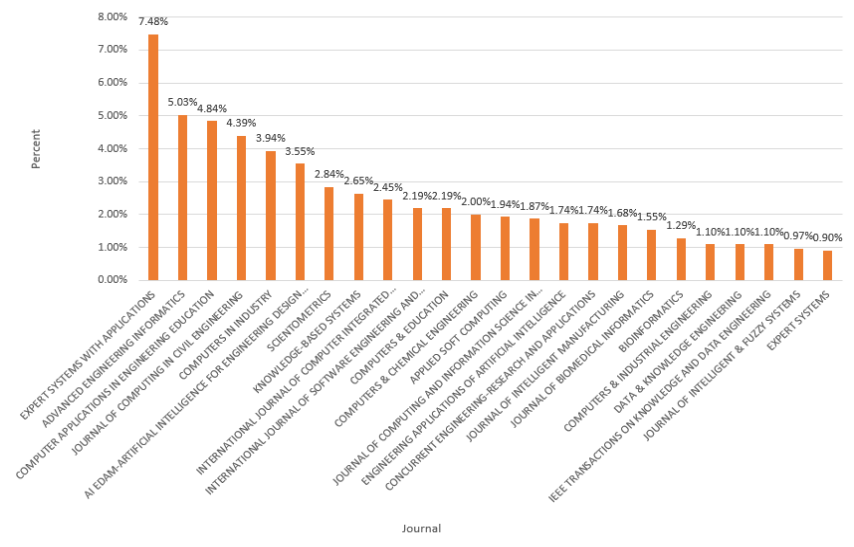

Figure 2. journal distribution

TABLE I. PART OF KeYWORD CORRELATION MATRIX

\begin{tabular}{|c|c|c|c|c|c|c|}
\hline & Ontology & $\begin{array}{l}\text { Knowledge } \\
\text { engineering }\end{array}$ & $\begin{array}{c}\text { Knowledge } \\
\text { management }\end{array}$ & $\begin{array}{c}\text { Ontology } \\
\text { engineering }\end{array}$ & $\begin{array}{c}\text { Knowledge } \\
\text { representation }\end{array}$ & $\begin{array}{c}\text { Knowledge- } \\
\text { based } \\
\text { engineering }\end{array}$ \\
\hline Ontology & 124 & 16 & 10 & 6 & 12 & 1 \\
\hline Knowledge management & 10 & 3 & 51 & 5 & 2 & 3 \\
\hline Ontology engineering & 6 & 1 & 5 & 45 & 5 & 1 \\
\hline
\end{tabular}


field of knowledge engineering, researchers would publish their fresh and novel related papers or find fresh topic content.

\section{Analysis of highly cited papers}

In descending order of the order in which the documents are cited, select top10 as shown in the following TABLE II. According to the content of the article, the authors try to analysis the distribution of research topics in the field.

As can be seen from TABLE II, the most cited is Natural Language Processing (Almost) from Scratch [6] written by Professor Collobert, R et al, cited as 1010 times. This paper is one of the most classic papers of neural network language model and word embedding. Its core goal is to train good word embedding to complete tasks such as part-of-speech tagging, phrase recognition, named entity recognition and semantic role tagging. This paper provides a good idea for the future use of neural networks for specific natural language processing tasks. NLP technology can be used for text mining, analysis of natural language texts, discovery of conceptual relationships between knowledge points and knowledge points, and assisting in knowledge acquisition for large-scale knowledge engineering. Use NLP technology as a tool to practice knowledge engineering.
In August 1977, Edward Feigenbaum proposed the concept of knowledge engineering for the first time. Since then, knowledge engineering has been a foundation of expert systems (also known as knowledge-based system) [7]. Since the beginning of the 21th century, the knowledge engineering's evolution has been focused on big data. A vast amount of data is generated and processed every day, and accessible content on the Internet is far beyond the exploration capabilities of data consumers, who usually can't locate the relevant information within an acceptable time frame. To cope with the challenges brought by the big data phrase of knowledge engineering's evolution, BigKE (Knowledge engineering with Big Data) [8] uses its frame work to offer several advantages over conventional knowledge engineering.

\section{ANALYSIS OF MAINSTREAM RESEARCH TOPIC}

Knowledge engineering is an applied science with its rich research fields. Topic analysis is a method of content analysis that understands the internal state of development of a discipline. The author intends to use high-frequency keywords to co-occurrence matrix and analyze several mainstream subject areas of knowledge engineering research, and to study knowledge engineering from a vertical direction.

TABLE II. Most Cited PAPER ToP Ten

\begin{tabular}{|c|c|c|c|c|}
\hline Author name & Title & Publication Name & Cited_Times & Year_Published \\
\hline $\begin{array}{l}\text { Collobert, R; Weston, } \\
\mathrm{J} \text {; et al. }\end{array}$ & $\begin{array}{l}\text { Natural Language Processing (Almost) } \\
\text { from Scratch }\end{array}$ & $\begin{array}{l}\text { JOURNAL OF MACHINE LEARNING } \\
\text { RESEARCH }\end{array}$ & 1010 & 2011 \\
\hline $\begin{array}{l}\text { Wu, XD; Zhu, XQ; et } \\
\text { al. }\end{array}$ & Data Mining with Big Data & $\begin{array}{lcr}\text { IEEE } & \text { TRANSACTIONS } & \text { ON } \\
\text { KNOWLEDGE } & \text { AND } & \text { DATA } \\
\text { ENGINEERING } & & \\
\end{array}$ & 700 & 2014 \\
\hline $\begin{array}{l}\text { Margaryan, } A ; \\
\text { Littlejohn, A; Vojt, G }\end{array}$ & $\begin{array}{l}\text { Are digital natives a myth or reality? } \\
\text { University students' use of digital } \\
\text { technologies }\end{array}$ & COMPUTERS \& EDUCATION & 256 & 2011 \\
\hline $\begin{array}{l}\text { Hwang, GJ; Chang, } \\
\text { HF }\end{array}$ & $\begin{array}{l}\text { A formative assessment-based mobile } \\
\text { learning approach to improving the } \\
\text { learning attitudes and achievements of } \\
\text { students }\end{array}$ & COMPUTERS \& EDUCATION & 235 & 2011 \\
\hline Rendle, $\mathrm{S}$ & Factorization Machines with libFM & $\begin{array}{lcr}\text { ACM } & \text { TRANSACTIONS } & \text { ON } \\
\text { INTELLIGENT } & \text { SYSTEMS } & \text { AND } \\
\text { TECHNOLOGY } & & \\
\end{array}$ & 210 & 2012 \\
\hline $\begin{array}{l}\text { Demirkan, H; Delen, } \\
\text { D }\end{array}$ & $\begin{array}{l}\text { Leveraging the capabilities of service- } \\
\text { oriented decision support systems: } \\
\text { Putting analytics and big data in cloud }\end{array}$ & DECISION SUPPORT SYSTEMS & 181 & 2013 \\
\hline $\begin{array}{l}\text { Barnaghi, P; Wang, } \\
\text { W; et al. }\end{array}$ & $\begin{array}{l}\text { Semantics for the Internet of Things: } \\
\text { Early Progress and Back to the Future }\end{array}$ & $\begin{array}{llr}\text { INTERNATIONAL } & \text { JOURNAL } & \text { ON } \\
\text { SEMANTIC } & \text { WEB } & \text { AND } \\
\text { INFORMATION SYSTEMS } & \end{array}$ & 164 & 2012 \\
\hline $\begin{array}{l}\text { Chu, HC; Hwang, GJ; } \\
\text { Tsai, CC }\end{array}$ & $\begin{array}{l}\text { A knowledge engineering approach to } \\
\text { developing mindtools for context-aware } \\
\text { ubiquitous learning }\end{array}$ & COMPUTERS \& EDUCATION & 154 & 2010 \\
\hline $\begin{array}{l}\text { Li, JZ; Tang, J; Li, Y; } \\
\text { Luo, Q }\end{array}$ & $\begin{array}{l}\text { RiMOM: A Dynamic Multistrategy } \\
\text { Ontology Alignment Framework }\end{array}$ & 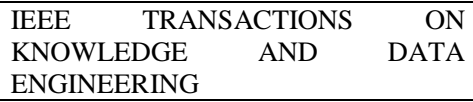 & 138 & 2009 \\
\hline $\begin{array}{l}\text { Lu, JW; Liong, VE; et } \\
\text { al. }\end{array}$ & $\begin{array}{lccc}\text { Learning } & \text { Compact } & \text { Binary } & \text { Face } \\
\text { Descriptor for Face Recognition } & \end{array}$ & $\begin{array}{lc}\text { IEEE } & \text { TRANSACTIONS } \\
\text { PATTERN } & \text { ANALYSIS } \\
\text { MACHINE INTELLIGENCE }\end{array}$ & 135 & 2015 \\
\hline
\end{tabular}


TABLE III. PART OF KEYWORD CORRELATION MATRIX

\begin{tabular}{|c|c|c|c|c|c|c|}
\hline & Ontology & $\begin{array}{l}\text { Knowledge } \\
\text { engineering }\end{array}$ & $\begin{array}{c}\text { Knowledge } \\
\text { management }\end{array}$ & $\begin{array}{c}\text { Ontology } \\
\text { engineering }\end{array}$ & $\begin{array}{c}\text { Knowledge } \\
\text { representation }\end{array}$ & $\begin{array}{c}\text { Knowledge-based } \\
\text { engineering }\end{array}$ \\
\hline Ontology & 1 & 0.15316792 & 0.125749 & 0.080322 & 0.164337 & 0.016396 \\
\hline Knowledge engineering & 0.153168 & 1 & 0.044781 & 0.015891 & 0.162564 & 0.019462 \\
\hline Knowledge management & 0.125749 & 0.04478111 & 1 & 0.104371 & 0.042708 & 0.076696 \\
\hline Ontology engineering & 0.080322 & 0.01589104 & 0.104371 & 1 & 0.113666 & 0.027217 \\
\hline Knowledge representation & 0.164337 & 0.16256402 & 0.042708 & 0.113666 & 1 & 0.027842 \\
\hline Knowledge-based engineering & 0.016396 & 0.01946247 & 0.076696 & 0.027217 & 0.027842 & 1 \\
\hline Expert system & 0.016396 & 0.11677484 & 0 & 0 & 0.055685 & 0 \\
\hline Machine learning & 0.032791 & 0.07784989 & 0 & 0 & 0.027842 & 0 \\
\hline Knowledge acquisition & 0.016676 & 0.09897595 & 0.078008 & 0.083045 & 0.056637 & 0.067806 \\
\hline Knowledge-based systems & 0.050913 & 0.12087344 & 0.026463 & 0.028172 & 0.057639 & 0.034503 \\
\hline
\end{tabular}

Since the frequency of occurrence of each keyword itself is different, in order to eliminate the influence of the difference on the analysis below, the co-occurrence matrix is converted into the correlation matrix by Ochiia coefficients, as show in TABLE III (part).The formula for calculating the Ochiia coefficient is as follows: the Ochiia coefficient of keywords K1 and K2 equals the number of co-occurrence of $\mathrm{K} 1$ and $\mathrm{K} 2$ is divided by $\mathrm{A}$, and $\mathrm{A}$ is equal to the square of the product of the frequency of $\mathrm{K} 1$ and $\mathrm{K} 2$. According to the formula, the transformation of the co-occurrence matrix and the correlation matrix conduct.

The data in the correlation matrix is similar data, and its numerical value indicates the distance and similarity between the two keywords, that is, the larger the value, the closer the distance between the two keywords, the better the similarity [10]. In order to reduce the larger error caused by too many 0 values in the correlation matrix, the matrix is further transformed into a similar matrix, the larger the value, the closer the two keywords.

On the basis of the correlation matrix, get the hierarchical clustering. Euclidean Square Distance have been selected the measured range the in the process cluster analysis. The Average Linkage have been used for the distance of the clusters through the agglomerative hierarchical clustering technique. The result as Fig. 3 as below. According the research, the list of keywords frequency and the semantic relations between the keywords, the cluster tree divided into four sections: Smart learning and education, Knowledge acquisition, Knowledge basic algorithms and Knowledge engineering technology application.

\section{A. Smart Learning and Education}

Knowledge grid realizes the orderly organization and knowledge discovery of domain knowledge, which is the ideal environment for learning. The knowledge grid adopts ontology modeling based on description logic, which can realize reasoning and has great application prospects for satisfying individualized learning and guiding learning process [11]. The current far-reaching application of information technology in the field of education is about the study of educational

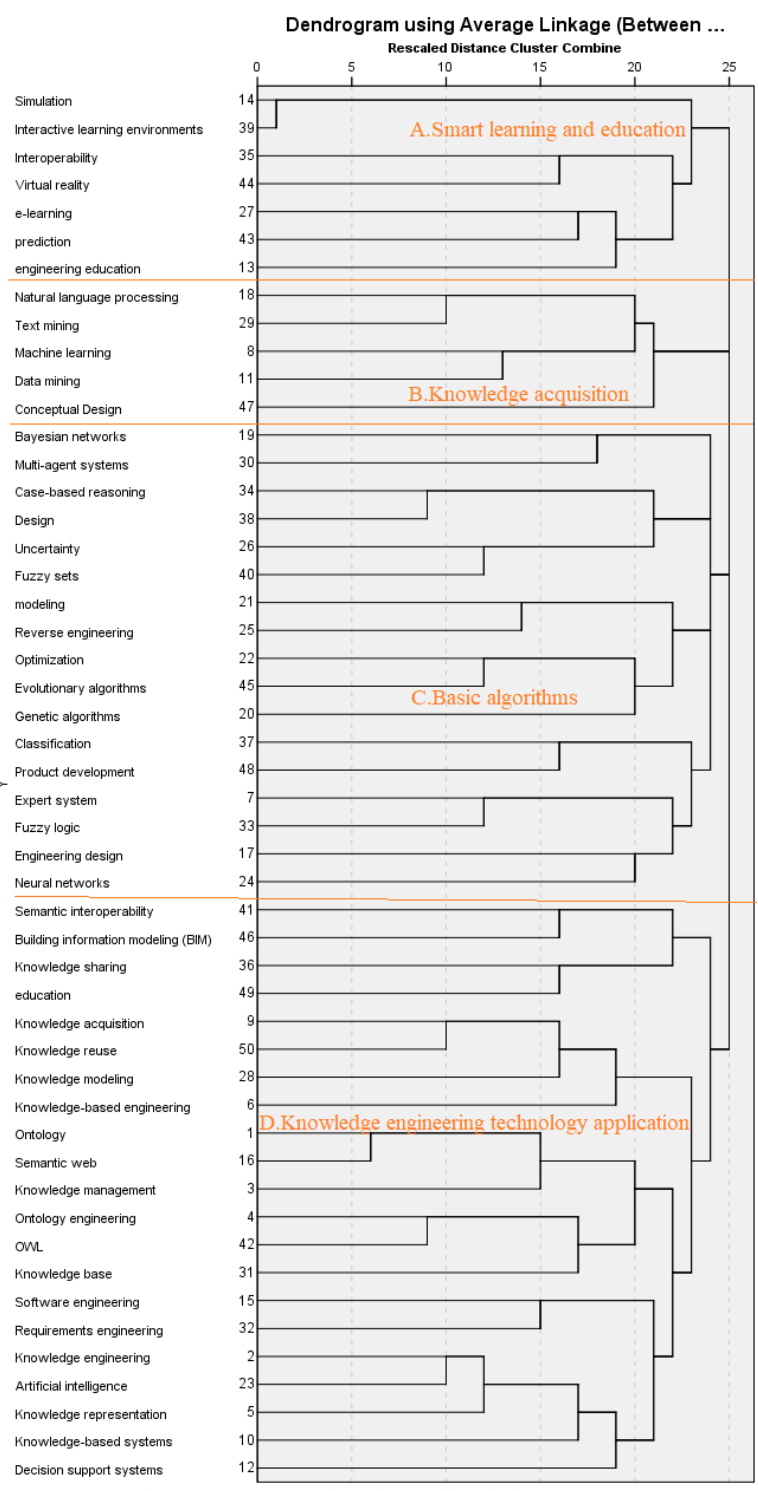

Figure 3. Keywords Hierarchical cluster tree 
metadata, such as the Dublin Education Metadata Standard DC-Education and the IEEE-LOM Learning Object Model.

\section{B. The Key Techniques of Knowledge Acquisition}

"Technology" is the foundation for the application and innovation of knowledge engineering to realize its knowledge. This means. In the modern era of rapid development of modern information technology, key techniques of knowledge engineering are constantly innovating and advancing. "Knowledge Acquisition (KA)" is the process of extracting various expertise for problem solving from knowledge sources and transforming it into executable code on a computer [12]. Emerging knowledge acquisition techniques have Data mining, Web mining, text mining, etc., these techniques will help knowledge extraction in knowledge engineering and promote knowledge engineering to a deeper level.

\section{Basic knowledge algorithms}

Any calculation that follows the laws of nature can be called Computational Intelligence, sometimes called Soft Computing. It mainly includes three contents: fuzzy computing, which is introduced by human processing, fuzzy computing, which is based on the working rules of biological neural networks, and genetic algorithms and evolutionary calculations that mimic the "survival of the fittest" rule in the biological world (Evolution computing).

Machine learning processes can be effectively integrated into knowledge engineering pipelines using commonly available software frameworks that incorporate the mathematics and algorithms needed to perform deeper analysis than was possible before. Machine learning approaches fall into two broad classes: supervised learning and unsupervised learning. The supervised algorithms are given labelled training data, whereas unsupervised learning algorithms find structure within the input data. The construction of a knowledge engineering pipeline will typically need to leverage algorithms from both classes.

\section{Knowledge Engineering Technology Application}

Data science and technology have received widespread attention. Data-centric research methods and techniques in information, energy, medicine, sociology, etc. Various subject areas have been widely applied and recognized. Driven by the wave of urban informatization and the rise of data science, smart cities have become the new ideas and new practices of the next generation of urbanization on a global scale. "Smart City is built on the basic framework of digital cities. It is connected to the real city through the ubiquitous sensor network. The massive data storage, calculation, analysis and decision-making are handled by the cloud computing platform, and the results of the analysis decision are Automated control of various facilities" [13]. The information system as a smart city must have powerful computing power, sensing ability and data application capability, which will become the research field of knowledge engineering.

\section{CONCLUSION}

With the help of the co-word analysis method, this paper analyzes the research topic in the field of knowledge engineering more intuitively and scientifically, and has made in-depth discussion, which has certain practical significance. Through the analysis of the authors, the following conclusions were obtained.

Starting from the analysis of the research topic based on co-word method. The word distribution of each document is used to establish a co-word matrix with lemmatization. After transforming it into a correlation matrix, it is hierarchically clustered by SPSS, and finally four subject groups are selected. In-depth content analysis, sorted out their main research content and hotspots.

\section{ACKNOWLEDGMENT}

This article has been helped, reviewed, and guided by Dr. Zheng Liu. I would like to express my heartfelt gratitude and sincere respect to her. The perseverance of the spirit of Dr. Liu, the profound knowledge, the work attitude of the facts, the generosity and the spirit of selfless dedication have always inspired me to constantly learn knowledge and pursue the realm of life. Thanks Dr. Haibo Li for his suggestion to modify the content of the article. There are too many people who have helped me, sincerely thank all those who care and help me, thank them for giving me the power to overcome myself, transcend myself, and constantly pursue, thank you all.

\section{REFERENCES}

[1] Qin H. Knowledge Discovery Through co-cord Analysis[J].Library Trends, 1999,48(1):pp.133-159.

[2] L. D. Baker and A. McCallum. Distributional clustering of words for text classification. In ACM SIGIR, 1998, pp. 96-103.

[3] Wang Yuefen. Comprehensive study of bibliometrics and content analysis[D]. Wuhan: Wuhan University, 2007.

[4] https://www.sketchengine.eu/my_keywords/lemmatization/.

[5] https://towardsdatascience.com/stemming-lemmatization-whatba782b7c0bd8.

[6] Collobert R , Weston J , Bottou L , et al. Natural Language Processing (Almost) from Scratch[J]. Journal of Machine Learning Research, 2011.

[7] R. Studer, V.R. Benjamins, and D. Fensel, "Knowledge Engineering: Principles and Methods," Data \& Knowledge Eng., vol. 25, no. 1, 1998, pp. 161-197

[8] Wu X D, Chen H H, Wu G Q, et al. Knowledge engineering with big data[J]. IEEE Intelligent Systems, 2015, 30(5):46-55.

[9] Xiao Zhixiong, Gu Jing. Analysis of hotspots in domestic collaborative research based on co-word analysis [J]. Intelligence Exploration,2015(5): pp.6-14.

[10] Key Technologies of Knowledge Measurement, Reasoning and Fusion in Knowledge Engineering Research [D]. Shanghai: Fudan University, 2004.

[11] https://towardsdatascience.com/stemming-lemmatization-whatba782b7c0bd8.

[12] Ma Chuangxin. On Knowledge Representation [J]. Modern Intelligence, 2014, 34(3): pp.21-28.

[13] Li Deren, Shan Jie, Shao Zhenfeng, et al. Geomatics for Smart CitiesConcept, Key Techniques, and Applications[J]. Geospatial Information Science, 2013, 16(3): pp.13-24. 